\title{
From bioblasts to mitochondria: ever expanding roles of mitochondria in cell physiology
}

\begin{abstract}
Brian O'Rourke*
Bernard Laboratory of Fundamental Research in Preventive Cardiology, Institute of Molecular Cardiobiology, Johns Hopkins University, Baltimore, MD, USA *Correspondence: bor@jhmi.edu
\end{abstract}

\section{HISTORICAL PERSPECTIVE}

Science's fascination with mitochondria spans more than 120 years, and whenever I find time for a respite from grant deadlines and other obligations, I enjoy following a trail of references back through the ages. I recall a few years ago finding a treasure after a quick search of our library's online catalog - an 1890 edition of "Die elementarorganismen und ihre beziehungen zu den zellen" by Richard Altmann (Altmann 1890). This tome is recognized as a transformative early histological description of mitochondria, or in his terminology, "bioblasts" (life germs), which he believed were autonomous elementary organisms responsible for metabolic and genetic functions. Even more surprisingly, I could simply request to have the volume delivered to me from the reserves as an ordinary loan. Paging through the yellowed leaves, I was amazed by the accuracy and beauty of the drawings (see Figure 1), and I was compelled to spend half a day scanning the figures into my computer (of course, I now find that a pdf is available on Google Books http://books.google. com/books?id=hLhUAAAAMAAJ\&oe $=\mathrm{U}$ TF-8). Characterizing them as the "living beings" of the cell, Altmann was clearly captivated by mitochondria, although his enthusiastic spirit was dampened by scathing criticism from his peers, including Professor F.P. Mall, who at one time headed the Anatomy Department of Johns Hopkins and was working in Leipzig at the time (Cowdry, 1953). Apparently, Altmann did not fare well under the onslaught and became a recluse in his own office, earning the nickname "the ghost" (Cowdry, 1953), only to pass away in 1900 . Nevertheless, his notion that mitochondria resembled bacteria, and had metabolic and genetic functions were, in the end, not far from the truth; borne out by the theory of endosymbiosis (Wallin, 1927; Margulis, 1970), the role of mitochondria in genetic (albeit maternal) inheritance (Payne, 1909; Schapira, 2006) and energy metabolism (Kingsbury, 1912;
Chance and Williams, 1955; Mitchell, 1961; Lehninger and Wadkins, 1962; Krebs, 1970; Nicholls and Ferguson, 2002).

The seeds of several areas of interestimportant to modern mitochondrial biologists can also be found in the literature of the early 20th century. For example, an interesting review of the state-of-the-art of mitochondrial research in 1918 by Cowdry (Cowdry, 1918) (available at http://www.archive.org/ download/carnegieinstitut2711918carn/ carnegieinstitut2711918carn.pdf) discusses fragmentation of mitochondria at the onset of degenerative tissue injury, the fission and fusion of mitochondria in living cells (see also the elegant work of Lewis and Lewis, 1915), the role of mitochondria in tissue regeneration, inheritance, metabolism, and respiration, among other possible functions. Also around this time, the close correlation between oxygen consumption and muscle work was being investigated (Evans and Matsuoka, 1915). Somewhat later, the ability of mitochondria to avidly take up $\mathrm{Ca}^{2+}$ was noted (see historical view in Carafoli, 2003) and this important ability has emerged as a crucial regulator of both intracellular $\mathrm{Ca}^{2+}$ balance and energy supply and demand. Of course, this process, taken to the extreme, can also trigger a mitochondrial permeability transition and cell death.

In launching a new journal called "Frontiers in Mitochondrial Physiology", it is worth considering that each major new idea involving mitochondria has at one time or another been roundly criticized. The preeminent case in point was the radical chemiosmotic hypothesis of Mitchell. Anyone who reads the history of this period (a fascinating account is given in Prebble and Weber, 2003) will recognize that new ideas in mitochondrial biology (as in other disciplines) have a tough time breaking down entrenched dogma. Who today would have the wherewithal or persistence to establish one's own institute to prove a point? Indeed, the limitations of the contemporary technology at the time made proof of the elegant idea of chemiosmosis difficult to come by initially. Nevertheless, as technology progressed, including membrane potential measurements and improved ion detection methods, the case was made stronger, but it still took more than a decade to become widely accepted. Indeed, new technologies are emerging at a rapid pace and are providing new insights into the regulation of mitochondrial function and the role of mitochondria in cell physiology. Most importantly, new approaches are helping to resolve some longstanding questions.

A major goal of this journal should be to keep the history of progress in mitochondrial research in mind so as not to prematurely discard novel ideas, and especially to avoid ad hominem attacks while promoting constructive criticism (no one should end up like Altmann!). In describing the tension between maintaining a healthy skepticism and being open to new ideas, Carl Sagan wrote that "at the heart of science is an essential balance between two seemingly contradictory attitudes - an openness to new ideas, no matter how bizarre or counterintuitive, and the most ruthlessly skeptical scrutiny of all ideas, old and new. This is how deep truths are winnowed from deep nonsense. The collective enterprise of creative thinking and skeptical thinking, working together, keep the field on track." I am sure we are all familiar with the occasional "ruthlessly skeptical" reviewer (or have assumed the role at one time or another), but let this quotation serve as a reminder to never abandon our sense of openness to new ideas.

\section{WHERE DOES THE FUTURE LIE?}

While it is presumptuous to try to predict where mitochondrial research will go in the future, one thing that appears to be constant is that the multiple roles of mitochondria in cell physiology will continue to expand. There are certain important areas in which progress has been stymied for some time, but seem to be breaking free of the constraints imposed by technology. 


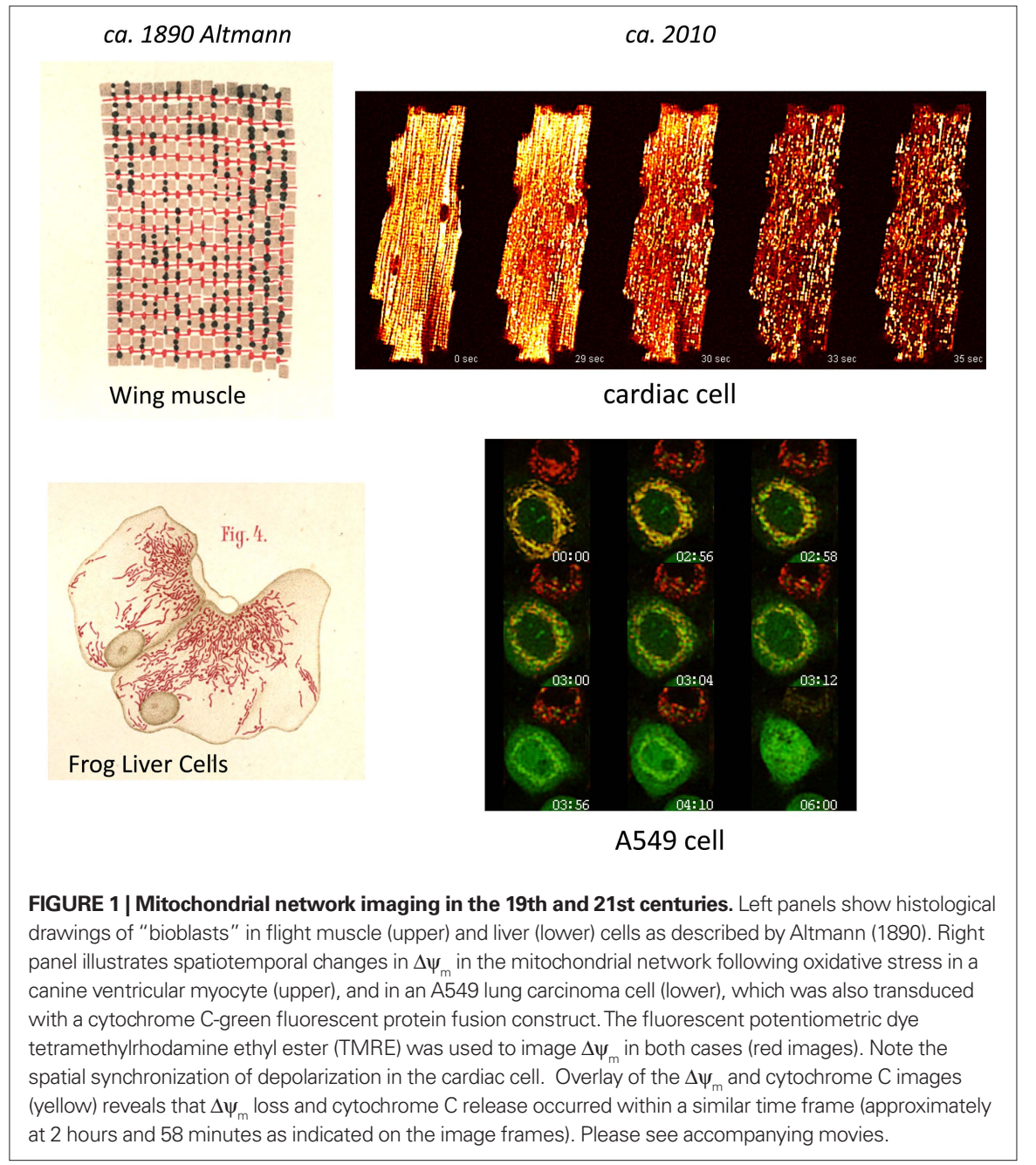

These include, but are certainly not limited to:

(1) Identification of ion transporters and channels - Presumably because the copy number of these proteins is small in the mitochondrial inner membrane, it has been very discouraging that the molecular structures of key ion transport proteins such as the mitochondrial $\mathrm{Ca}^{2+}$ uniporter and the permeability transition pore have not been resolved. Similarly, although new candidates mediating $\mathrm{K}^{+}$transport across the inner membrane and conferring resistance to cell injury continue to be reported, definitive molecular evidence is currently lacking. On the bright side, it is very exciting that several recent breakthroughs have been made regarding the proteins mediating $\mathrm{Ca}^{2+}$ efflux from the mitochondria. For example,
Clapham and colleagues, using an RNAi screen of the Drosophila genome (Jiang et al., 2009), identified a protein whose mammalian homolog, Letm 1 , appears to underlie mitochondrial $\mathrm{Ca}^{2+} / \mathrm{H}^{+}$antiport activity. Also recently reported, a unique isoform of the $\mathrm{Na}^{+}$/ $\mathrm{Ca}^{2+}$ exchanger family, NCLX, appears to be responsible for mitochondrial $\mathrm{Na}^{+}$-dependent $\mathrm{Ca}^{2+}$ efflux (Palty et al., 2010). These findings, along with the application of transgenic approaches to probe the structure of inner (Kokoszka et al., 2004; Baines et al., 2005; Nakagawa et al., 2005) and outer (Anflous et al., 2001; Krauskopf et al., 2006) membrane proteins promise to provide new insights into some of these old questions.

(2) Proteomics - New proteomic methods have opened the floodgates to the study of potential regulatory posttranslational modifications affecting mitochondrial enzymes, transporters, and complexes. These include phosphorylation, S-nitrosylation, acetylation, SUMOylation and others. In most cases, little is known about the functional effects of the observed modifications, which signaling pathways mediate them, where the signaling enzymes are localized, and how they are activated by intra- or extramitochondrial events. The scope of these questions should occupy investigators in the field for many decades.

(3) Mitochondria as signaling organelles - In addition to being targets of signaling pathways, mitochondria have emerged as important signal generators. Indeed, a resurgent interest in mitochondria was engendered by the linkage between mitochondrial injury and apoptosis (Green and Kroemer, 2004) and, more recently, an important role for mitochondria as sources of ROS that activate cytoplasmic signaling pathways that influence gene expression has emerged (Chandel et al., 2000). Mitochondria also modulate other cellular signals, for example, by influencing the kinetics and amplitude of $\mathrm{Ca}^{2+}$ signals, by controlling the local redox potential of other proteins, and by providing the energy to drive most cellular functions, which will critically depend on the spatial organization of the mitochondria with respect to the structures requiring a steady supply of ATP. Doubtless, many more interactions between mitochondria and other cell subsystems will be elucidated in the future.

(4) Interactions between the cytoskeleton and mitochondria - In recent years, investigation into the role of the cytoskeleton as not just a passive scaffold for mitochondria, but as an active participant in the motility, trafficking, and localization of mitochondria has blossomed (Anesti and Scorrano, 2006; Spat et al., 2008; Liu et al., 2009). These studies have provided a fascinating picture of how mitochondrial dynamics appears to involve directed movement of mitochondria along the microtubular network to localize them close to structures with a high energy demand, which depends in 
part on cytoplasmic $\mathrm{Ca}^{2+}$ signals. In addition to the question of how spatial organization influences mitochondrial function, there is also still much to learn about how the cytoskeleton directly modulates mitochondrial bioenergetics. Reports have indicated specific effects of cytoskeletal elements on transport through the outer membrane (Xu et al., 2001) or oxidative phosphorylation (Schroder et al., 2003) and there is longstanding evidence that mitochondria in isolation behave differently than those incorporated into the cytoskeletal scaffold (Appaix et al., 2003).

(5) MtDNA mutations and heteroplasmy - A burgeoning transdisciplinary interest in the role of mitochondrial mutations in disease has emerged since the identification of maternally inherited disorders (reviewed in Wallace, 2005). This area is ripe for further discovery as transgenic technologies are being applied (Fan et al., 2008). In terms of acquired mtDNA mutations, there is clearly a correlation between disease, aging, and accumulation of mtDNA mutations; however, due to the heteroplasmy of the mitochondrial population and differences from tissueto-tissue, what determines the point of functional collapse is still largely unknown in most pathologies. Another very interesting area is the contribution of natural variations in mitochondrial haplotypes to disease risk. Even single amino acid polymorphisms in mtDNA have been correlated with statistically significant differences in risk, begging the question of where and when a potential defect may be manifested in the lifetime of the subject.

(6) Regulation of the transcription, translation, and targeting of nuclear-encoded mitochondrial proteins. While the most fundamental aspects of transcriptional regulation of mtDNA- and nuclear-encoded mitochondrial proteins have been elucidated (for review see Scarpulla, 2008), there is still much to learn about how changes in energy demand, substrate supply and other factors bring about a coordinated response to increase or decrease oxidative phosphorylation capacity. A combination of factors including phosphorylation state, redox potential, $\mathrm{Ca}^{2+}$ signals, and nucleotide balance all play a role in modulating the master regulators of metabolic adaptation (such as PGC-1 $\alpha$ ), and it will likely take a systems biology approach to fully understand how mitochondrial biogenesis is coordinated and, more importantly, how this process is impaired during the progression of disease. Another area of increasing interest is the regulation of protein trafficking to the mitochondria. Fascinating new roles for endopeptidases are being uncovered, which indicate that protein redirection to (Boopathi et al., 2008) and from the mitochondria (Sik et al., 2004) may be a dynamically regulated process.

(7) Epigenetics - The ability of mitochondria to sense and adapt to environmental changes, often resulting in altered nuclear transcription through cytosolic signaling pathways, has recently led to the proposal that mitochondria play a major role in epigenetic modification of gene expression (Wallace, 2009). The high mutation rate of mtDNA and the fact that such changes are heritable (most evident in the case of mitochondrial diseases) also supports the idea that mitochondria can provide a significant evolutionary force.

Given the myriad roles of mitochondria in the life and death of the cell, it is quite astonishing what the simple act of endosymbiosis has led to. Of course the beneficial effects of maintaining the mitochondrial parasite have far outweighed the bother. In return for the cell providing a convenient shelter for survival - in essence a controlled environment with free food delivery, waste removal, help with reproduction, and defense mechanisms to fight intruders - the capacity of the mitochondrion for mass-energy transformation has enabled enormous feats of locomotion, the evolution of specialized organs to maintain food and oxygen delivery to the cells far away from the primary sources, the power to synthesize macromolecules on a large scale and eliminate toxic waste material, and, perhaps most importantly, the ability coordinate everything with an energy hungry brain and nervous system. Indeed, without mitochondria, it is quite possible that we may never have become self aware. If that's not an argument for upward causality, I don't know what is! For that we can be grateful to the mitochondria and return the favor by advancing our understanding of their function as far as is humanly possible. Hopefully, this journal will help us along the way.

\section{SUPPLEMENTARY MATERIAL}

The Supplementary Material for this article can be found online at http:// www.frontiersin.org/physiology/mitochondrialphysiology/paper/10.3389/ fphys.2010.00007/

\section{REFERENCES}

Altmann, R. (1890). Die Elementarorganismen Und Ihre Beziehungen $\mathrm{Zu}$ Den Zellen. Leipzig: Veit \& comp. 145.

Anesti, V., and Scorrano, L. (2006). The relationship between mitochondrial shape and function and the cytoskeleton. Biochim. Biophys. Acta 1757, 692-699.

Anflous, K., Armstrong, D. D., and Craigen, W. J. (2001). Altered mitochondrial sensitivity for ADP and maintenance of creatine-stimulated respiration in oxidative striated muscles from VDAC1-deficient mice. J. Biol. Chem. 276, 1954-1960.

Appaix, F., Kuznetsov, A. V., Usson, Y., Kay, L., Andrienko, T., Olivares, J., Kaambre, T., Sikk, P., Margreiter, R., and Saks, V. (2003). Possible role of cytoskeleton in intracellular arrangement and regulation of mitochondria. Exp. Physiol. 88, 175-190.

Baines, C. P., Kaiser, R. A., Purcell, N. H., Blair, N. S., Osinska, H., Hambleton, M.A., Brunskill, E. W., Sayen, M. R., Gottlieb, R. A., Dorn, G. W., Robbins, J., and Molkentin, J. D. (2005). Loss of cyclophilin D reveals a critical role for mitochondrial permeability transition in cell death. Nature 434, 658-662.

Boopathi, E., Srinivasan, S., Fang, J. K., and Avadhani, N. G. (2008). Bimodal protein targeting through activation of cryptic mitochondrial targeting signals by an inducible cytosolic endoprotease. Mol. Cell 32, 32-42.

Carafoli, E. (2003). Historical review: mitochondria and calcium: ups and downs of an unusual relationship. Trends Biochem. Sci. 28, 175-181.

Chance, B., and Williams, G. R. (1955). A method for the localization of sites for oxidative phosphorylation. Nature 176, 250-254.

Chandel, N. S., McClintock, D. S., Feliciano, C. E., Wood, T. M., Melendez, J. A., Rodriguez, A. M., and Schumacker, P. T. (2000). Reactive oxygen species generated at mitochondrial complex III stabilize hypoxiainducible factor-1alpha during hypoxia: a mechanism of O sensing. J. Biol. Chem. 275, 25130-25138.

Cowdry, E. V. (1918). The Mitochondrial Constituents of Protoplasm, vol. viii. Washington, DC: Carnegie Institution of Washington, VIII.

Cowdry,E.V.(1953). Historical background of research on mitochondria. J. Histochem. Cytochem. 1, 183-187.

Evans, C.L., and Matsuoka,Y.(1915). The effect of various mechanical conditions on the gaseous metabolism and efficiency of the mammalian heart. J. Physiol. (Lond.) 49, 378-405.

Fan, W., Waymire, K. G., Narula, N., Li, P., Rocher, C., Coskun, P.E., Vannan, M. A., Narula, J., Macgregor, G. 
R., and Wallace, D. C. (2008). A mouse model of mitochondrial disease reveals germline selection against severe mtDNA mutations. Science 319, 958-962.

Green,D.R., and Kroemer, G. (2004). The pathophysiology of mitochondrial cell death. Science 305, 626-629.

Jiang, D., Zhao, L., and Clapham, D. E. (2009). Genomewide RNAi screen identifies Letm 1 as a mitochondrial $\mathrm{Ca}^{2+} / \mathrm{H}^{+}$antiporter. Science 326, 144-147.

Kingsbury, B. F. (1912). Cytoplasmic fixation. Anat. Rec. $5,39-52$.

Kokoszka, J. E., Waymire, K. G., Levy, S. E., Sligh, J. E., Cai, J., Jones, D. P., MacGregor, G. R., and Wallace, D. C. (2004). The ADP/ATP translocator is not essentia for the mitochondrial permeability transition pore. Nature 427, 461-465.

Krauskopf, A., Eriksson, O., Craigen, W. J., Forte, M. A., and Bernardi, P. (2006). Properties of the permeability transition in VDAC1(-/-) mitochondria. Biochim. Biophys. Acta 1757, 590-595.

Krebs, H. A. (1970). The history of the tricarboxylic acid cycle. Perspect. Biol. Med. 14, 154-170.

Lehninger, A. L., and Wadkins, C. L. (1962). Oxidative phosphorylation. Annu. Rev. Biochem. 31, 47-78.

Lewis, M. R., and Lewis, W.H. (1915). Mitochondria (and other cytoplasmic structures) in tissue cultures. Am. J. Anat. 17, 339-401.

Liu, X., Weaver, D., Shirihai, O., and Hajnoczky, G. (2009). Mitochondrial 'kiss-and-run': interplay between mitochondrial motility and fusion-fission dynamics. EMBO J. 28, 3074-3089.

Margulis, L. (1970). Origin of Eukaryotic Cells; Evidence and Research Implications for a Theory of the Origin and Evolution of Microbial, Plant, and Animal Cells on the Precambrian Earth. New Haven: Yale University Press, 349.
Mitchell, P. (1961). Coupling of phosphorylation to electron and hydrogen transfer by a chemi-osmotic type of mechanism. Nature 191, 144-148.

Nakagawa, T., Shimizu, S., Watanabe, T., Yamaguchi, O., Otsu, K., Yamagata, H., Inohara, H., Kubo, T. and Tsujimoto, Y. (2005). Cyclophilin D-dependent mitochondrial permeability transition regulates some necrotic but not apoptotic cell death. Nature 434, 652-658.

Nicholls, D. G., and Ferguson, S. J. (2002). Bioenergetics 3rd Edn. London: Academic Press, 297.

Palty, R., Silverman, W. F., Hershfinkel, M., Caporale, T., Sensi, S. L., Parnis, J., Nolte, C., Fishman, D., ShoshanBarmatz, V., Herrmann, S., Khananshvili, D., and Sekler, I. (2010). NCLX is an essential component of mitochondrial $\mathrm{Na}^{+} / \mathrm{Ca}^{2+}$ exchange. Proc. Natl. Acad. Sci. U.S.A. 107, 436-441.

Payne, F. (1909). The chondriosomes as bearers of the hereditary qualities. Am. Nat. 43, 190-192.

Prebble, J., and Weber, B. (2003). Wandering in the Gardens of the Mind: Peter Mitchell and the Making of Glynn. New York: Oxford University Press, 324.

Scarpulla, R. C. (2008). Transcriptional paradigms in mammalian mitochondrial biogenesis and function. Physiol. Rev. 88, 611-638.

Schapira, A. H. (2006). Mitochondrial disease. Lancet $368,70-82$.

Schroder, R., Goudeau, B., Simon, M. C., Fischer, D., Eggermann, T., Clemen, C. S., Li, Z., Reimann, J., Xue, Z., Rudnik-Schoneborn, S., Zerres, K., van der Ven, P. F., Furst, D. O., Kunz, W. S., and Vicart, P. (2003). On noxious desmin: functional effects of a novel heterozygous desmin insertion mutation on the extrasarcomeric desmin cytoskeleton and mitochondria. Hum. Mol. Genet. 12, 657-669.
Sik, A., Passer, B. J., Koonin, E. V., and Pellegrini, L. (2004). Self-regulated cleavage of the mitochondrial intramembrane-cleaving protease PARL yields Pbeta, a nuclear-targeted peptide. J. Biol. Chem. 279, 15323-15329.

Spat, A., Szanda, G., Csordas, G., and Hajnoczky, G. (2008). High- and low-calcium-dependent mechanisms of mitochondrial calcium signalling. Cell Calcium 44, 51-63.

Wallace, D.C. (2005). A mitochondrial paradigm of metabolic and degenerative diseases, aging, and cancer: a dawn for evolutionary medicine. Annu. Rev. Genet. 39, 359-407.

Wallace, D. C. (2009). Mitochondria, bioenergetics, and the epigenome in eukaryotic and human evolution. Cold Spring Harb. Symp. Quant. Biol. [Epub ahead of print].

Wallin, I. (1927). Symbionticism and the Origin of Species. Baltimore, Williams \& Wilkins Co., 171.

Xu, X., Forbes, J. G., and Colombini, M. (2001). Actin modulates the gating of Neurospora crassa VDAC. J. Membr. Biol. 180, 73-81.

Received: 20April 2010; accepted: 21 April 2010; published online: 15 June 2010.

Citation: O'Rourke B (2010) From bioblasts to mitochondria: ever expanding roles of mitochondria in cell physiology. Front. Physio. 1:7. doi: 10.3389/fphys.2010.00007

This article was submitted to Frontiers in Mitochondrial Research, a specialty of Frontiers in Physiology.

Copyright (C) 2010 O'Rourke. This is an open-access article subject to an exclusive license agreement between the author and the Frontiers Research Foundation, which permits unrestricted use, distribution, and reproduction in any medium, provided the original authors and source are credited. 